\title{
Especie nueva de Sloanea (Elaeocarpaceae) de Guerrero y Chiapas, México
}

\section{A new species of Sloanea (Elaeocarpaceae) from Guerrero and Chiapas, Mexico}

\author{
Lucio Lozada-Pérez \\ Facultad de Ciencias, Universidad Nacional Autónoma de México. Apartado postal 70-283, 04510. México, D.F., México. \\ Correspondencia: luciolozada@hotmail.com
}

\begin{abstract}
Resumen. Se describe e ilustra Sloanea ahuatoso n. sp., con material recolectado en la sierra de Atoyac, Guerrero y en la Reserva de la Biosfera El Triunfo, Chiapas, México. La especie se caracteriza por una inflorescencia de un dicasio simple, con sólo una flor en la madurez, botones florales cerrados, sépalos carnosos, densamente tomentosos en el lado abaxial, cápsulas elipsoides y semillas elipsoides completamente cubiertas por un arilo anaranjado. Por el tipo de inflorescencia y los botones florales cerrados se incluye en el subgénero Quadrisepala. Se discute su relación con las especies del subgénero.
\end{abstract}

Palabras clave: Chiapas, Elaeocarpaceae, Guerrero, México, Sloanea.

\begin{abstract}
Sloanea ahuatoso n. sp., is described from material collected in the mountain range of Atoyac, Guerrero, and the Reserva de la Biosfera El Triunfo, Chiapas, Mexico. This species is characterized by its simple dichasial inflorescence, closed flower buds, fleshy sepals with dense tomentum abaxially, ellipsoidal capsules, and ellipsoidal seeds completely covered with an orange-colored aril. It is included in subgenus Quadrisepala for the inflorescence type and the closed flower buds. Its relationship with other species of the subgenus is discussed.
\end{abstract}

Key words: Chiapas, Elaeocarpaceae, Guerrero, Mexico, Sloanea.

\section{Introducción}

El estudio de un bosque mesófilo de montaña en la localidad de El Molote, municipio de Atoyac de Álvarez, Guerrero, México, para el proyecto de la flora del estado de Guerrero que se realiza en la Facultad de Ciencias de la Universidad Nacional Autónoma de México, permitió la recolección detallada de varias plantas interesantes y poco conocidas. Una de estas plantas es un árbol del género Sloanea que no fue posible identificar después de revisar los ejemplares de los herbarios ENCB, FCME, MEXU y la literatura correspondiente. En este proceso de se encontró un ejemplar con frutos del estado de Chiapas con las mismas características de la planta de Guerrero pero mal identificado. Debido a sus claras diferencias con las especies conocidas se propone que los ejemplares de Guerrero y Chiapas corresponden a una especie nueva que aquí se describe.

Recibido: 09 marzo 2006; aceptado: 15 abril 2008

\section{Descripción}

Sloanea ahuatoso n. sp. (Fig. 1)

Tipo: MÉXICO.GUERRERO: Municipio de Atoyac de Álvarez. Loc. $0.3 \mathrm{~km}$ al O de El Molote, $17^{\circ} 25^{\prime} 28.2^{\prime \prime} \mathrm{N}$, $100^{\circ} 10^{\prime} 21$ " O, cafetal en bosque mesófilo de montaña, 1 725 m, 5 diciembre 1999, J. Rojas 102 (holotipo, FCME; isotipos, MEXU, ENCB, XAL).

S. terniflorae similis, differt sepalis viridibus vel luteolis, carnosis, 10-14 longis, 7-11 mm latis, late ovatis, apice acuto, margine externo dilatato, dense tomentosis subter, pedicellis et capsulis longioribus, fructibus monospermis, semine 2.5-3 cm longo, 0.9-2 cm lato, arillo omnino obsito.

Árboles hasta de $25 \mathrm{~m}$ de alto, con contrafuertes hasta de $3 \mathrm{~m}$ de alto, perímetro por arriba de los contrafuertes de 1.3-1.6 m; corteza externa rojiza, rugosa, con lenticelas prominentes, corteza interna blanca, tornándose ligeramente amarillenta, ramillas densamente tomentosas. Hojas alternas, concentradas hacia el ápice de las ramas; 


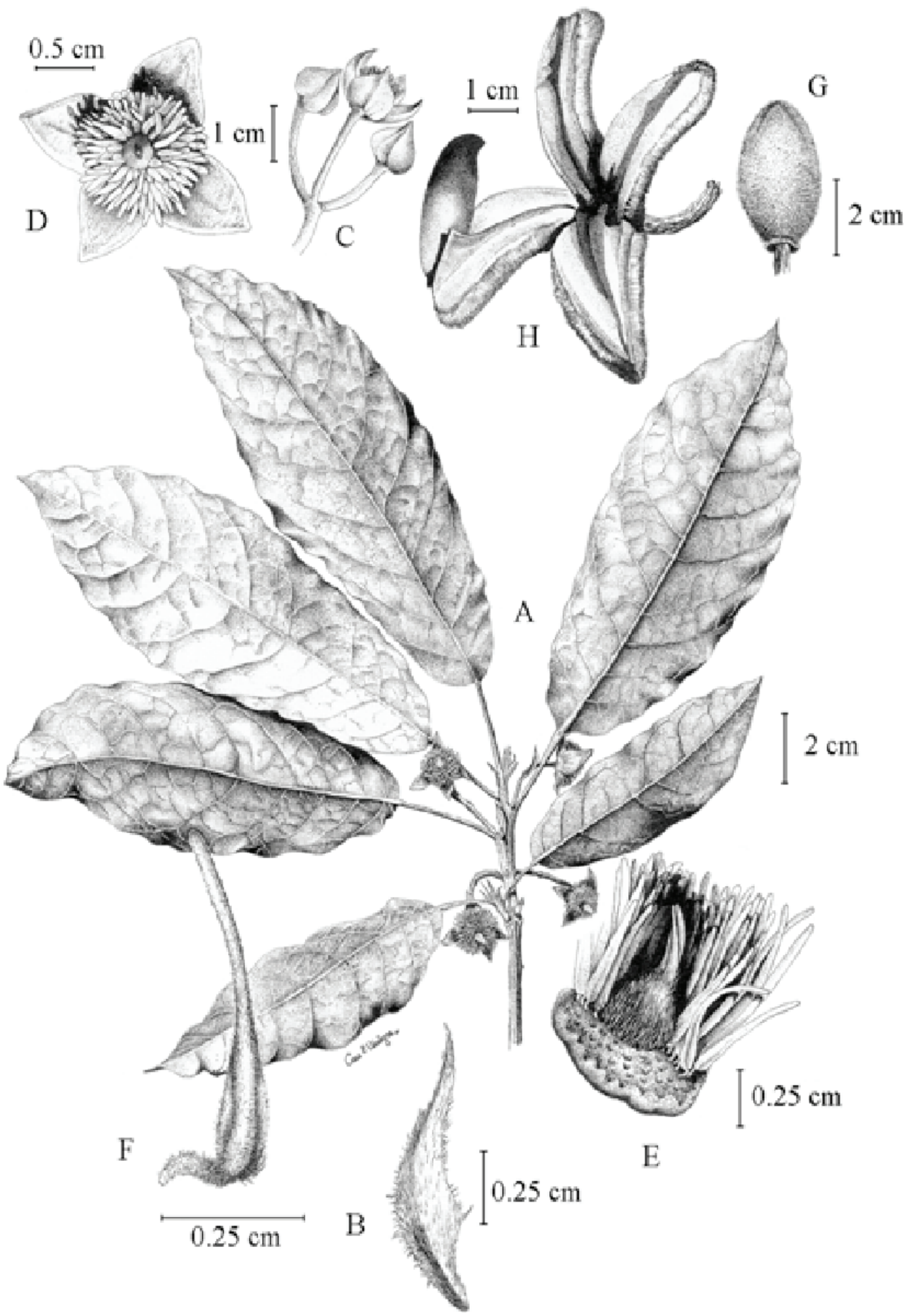

Figura 1. Sloanea ahuatoso sp. nov. A, rama con flores; B, estípula; C, inflorescencia; D, flor (vista apical); E, receptáculo con ovario y estambres; F, estambre; G, fruto; H, fruto abierto mostrando la semilla. A-F tomados de Rojas 102, G y H tomados de Lozada 2016. Todos en FCME. 
láminas de 10-18 x 3.5-8 cm, estrechamente obovadas a elípticas u oblongas, ápice acuminado, ligeramente achatado y emarginado, margen entero a sinuado hacia la mitad superior, base redondeada a obtusa o ligeramente cordada, venación pinnada, 8-10 pares de venas laterales, haz glabra, pero con la vena central densa a esparcidamente tomentosa, envés glabro, excepto a lo largo de la vena central y las venas laterales, estas tomentosas, más densamente en las axilas; pecíolos de 2-4.5 cm de largo, tomentosos a tomentulosos, pulvínulo poco evidente, de color oscuro, densamente tomentoso; estípulas deciduas, de 7-10 x 1.4-2.6 mm, lanceoladas, densamente tomentosas. Inflorescencia un dicasio simple, en la madurez sólo una flor, de 2.5-4.0 cm de largo; pedúnculos de $0.5-2.5 \mathrm{~cm}$ de largo, densamente tomentosos; pedicelos de 1.7-2.3 cm de largo, densamente tomentosos; brácteas y bractéolas deciduas, de 8-10 x 3-3.5 mm, lanceoladas a estrechamente ovadas, asimétricas, margen con 1-2 dientes por lado, ambos lados de esparcida a densamente tomentosos. Flores de color verde claro a amarillo pálido, sépalos 34, carnosos, valvados, de 10-14 x 7-11 mm, ampliamente ovados a ovados, ápice agudo, margen externo engrosado, densamente tomentosos del lado abaxial y del adaxial sólo en el margen, el resto de la superficie esparcidamente tomentoso, receptáculo cuadrangular, densamente velutino y fimbriado alrededor de la base del ovario; estambres 135-145, de 4.5-5 mm de largo, filamentos de ca. $1 \mathrm{~mm}$ de largo, densamente puberulentos, de color rosado pálido, anteras de 2-2.5 mm de largo, lanceoladas, abriéndose por un poro apical, que se agranda hacia la base, cortamente tomentosas con pelos antrorsos, el conectivo prolongándose por arriba de la antera en una arista de 1.5-2 mm de largo, curvada hacia atrás, densamente puberulenta, aplanada dorsoventralmente y estrechándose en forma gradual hacia el ápice; pistilo de 5 a $6 \mathrm{~mm}$ de largo por 2.5-3.0 $\mathrm{mm}$ de ancho, tri a tetralobado, densamente estrigoso, ovario de 3$3.5 \mathrm{~mm}$ de largo, ovoide, con 3-4 cavidades, placentación axilar, óvulos ca. 6 por cavidad, dispuestos en 2 hileras; estilos 3-4, de 1.5-2 mm de largo, fusionados, rectos a ligeramente contortos, estrigosos con pelos antrorsos en la mitad inferior. Cápsulas rojizas a pardas, receptáculo persistente en la base, de 4-5.4 x 2.8-3 cm, elipsoides, 34 valvadas, valvas de $3.5-5 \mathrm{~mm}$ de grueso, densamente cubiertas por espinas irritantes de $1.5-3 \mathrm{~mm}$ de largo, muy estrechamente clavadas, cubiertas con tricomas antrorsos y muy esparcidos, densos en el ápice, superficie interna densamente hirsútula, estilo persistente en el ápice de cada valva. Una semilla por fruto, de $2.5-3 \times 0.9-1.2 \mathrm{~cm}$, elipsoide, cubierta totalmente por un arilo anaranjado.

Distribución, hábitat y fenología. En Guerrero, Sloanea ahuatoso forma parte del bosque mesófilo de montaña caracterizado por lauráceas y Alfaroa costaricensis, entre
1650-2000 m de altitud. Florece de abril a septiembre y fructifica de julio a diciembre. Su hábitat gradualmente ha sido sustituido por cultivos de café. Sin embargo, individuos de esta especie y de otras que forman parte del bosque son utilizadas como sombra del café; de ahí, la importancia del llamado café de sombra. En Chiapas se encuentra en la Reserva de la Biosfera El Triunfo a $1350 \mathrm{~m}$ de altitud y fructifica en junio (sólo se conoce una recolecta con fruto).

\section{Resumen taxonómico}

Paratipos. MÉXICO. CHIAPAS: Mpio. Mapastepec, Reserva El Triunfo, Polígono 1, El Tomatal - El Limonar, $15^{\circ} 39^{\prime}$ N, $92^{\circ} 48^{\prime}$ O, Elev. 1350 m, 15 junio 1990, M. Heath y A. Long 1036 (FCME). GUERRERO: Mpio. Atoyac de Álvarez, $0.5 \mathrm{~km}$ al O de El Molote, $17^{\circ} 25^{\prime} 28^{\prime \prime} \mathrm{N}, 100^{\circ}$ 10' 21" O, Elev. 1725 m, 5 septiembre 1998, E. León 3 (FCME, MEXU, XAL). $0.5 \mathrm{~km}$ al O de El Molote, $17^{\circ} 25^{\text {' }}$ 25.4" N, 100 10' 25" O, Elev. 1690 m, 7 diciembre 2000, E. León 138 (FCME, MEXU, XAL). Puerto de la Piedra Acanalada, km 92 terracería Atoyac-Xochipala, Elev. 1 950 m, 6 enero 1984, L. Lorenzo 866 (FCME). $0.5 \mathrm{~km}$ al $\mathrm{O}$ de El Molote, $17^{\circ} 25^{\prime} 28.2^{\prime \prime} \mathrm{N}, 100^{\circ} 10^{\prime} 21$ " O, Elev. 1675 m, 25 abril 1998, L. Lozada 2016 (FCME, MEXU, XAL). $0.5 \mathrm{~km}$ al O de El Molote, $17^{\circ} 25^{\prime} 19.6^{\prime \prime} \mathrm{N}, 100^{\circ}$ 10' 25.5" O, Elev. 1750 m, 24 septiembre 1999, L. Lozada 2201 (FCME, MEXU, XAL). $0.5 \mathrm{~km}$ al O de El Molote, $17^{\circ} 25^{\prime}$ 28.2" N, 100'10' 21" O, Elev. 1750 m, 16 abril 1999, J. Rojas 39 (FCME, MEXU, XAL). $0.5 \mathrm{~km}$ al O de El Molote, $17^{\circ} 25$ ' 12.3” N, 100 10' 23.4” O, Elev. 1 750 m, 26 septiembre 1999, J. Rojas 43 (FCME, MEXU, XAL).

Etimología. El epíteto específico deriva de la palabra "ahuatoso", nombre con el que los habitantes de la localidad de El Molote llaman a los árboles de la especie, ya que en enero cuando se realiza la cosecha de café, las espinas del fruto se desprenden con el viento e irritan la piel de las personas que participan en la recolección.

\section{Comentarios taxonómicos}

Sloanea ahuatoso pertenece al subgénero Quadrisepala y a la sección Corimbo-racemi de la clasificación de Smith (1954), ya que posee botones florales cerrados, 3-4 sépalos iguales y flores dispuestas en una cima. El autor incluyó en la sección Corimbo-racemi a Sloanea amygdalina Griseb., S. garckeana K. Schum., S. kuhlmannii Ducke, y S. terniflora (Moc. et Sessé ex DC.) Standl. Sloanea amygdalina se encuentra restringida a Las Antillas y se 
separa de $S$. ahuatoso por los pedicelos hasta de $1.5 \mathrm{~cm}$ de largo, sépalos de 2-3 cm de ancho, el fruto subgloboso de 1.5-2.5 cm de largo y espinas del mismo de 1-1.5 mm de largo. Sloanea garckeana y S. kuhlmannii sólo se localizan en Sudamérica. La primera especie tiene, a diferencia de Sloanea ahuatoso, pecíolos más cortos de 0.5-2.8 cm de largo, brácteas lineares de $3 \mathrm{~mm}$ de largo, sépalos lanceolados de 6-7 x 2-4 mm, estilos de 2-4 mm de largo, frutos de 2.5-3.5 cm de largo y semillas de $12 \mathrm{~mm}$ de largo. La segunda también tiene pecíolos más cortos, hasta de $2.3 \mathrm{~cm}$ de largo y hojas subopuestas, pedicelos cortos hasta de $1 \mathrm{~cm}$ de largo, sépalos cortos de 7 x 3-6 mm de ancho y estilos hasta de $4 \mathrm{~mm}$ de largo. Sloanea terniflora es la especie de más amplia distribución pues se localiza desde Nayarit, en el oeste de México hasta Sudamérica; se puede separar de $S$. ahuatoso por tener hojas de textura más gruesa y el ápice redondeado a obtuso, pecíolos más cortos, de 0.3-2 cm de largo, pedicelos cortos, hasta 1.3 $\mathrm{cm}$ de largo, sépalos de color rojo cuando frescos y negros cuando secos (en S. ahuatoso no cambian de color, siempre son de color verde claro a amarillo pálido), también son más cortos, de 6-7 x 2-5 mm, así como cápsulas pequeñas, de $1.5-2.5 \mathrm{~cm}$ de largo.

Otra especie con frutos de espinas irritantes es Sloanea cruenta, descrita por Lundell (1975) pero de posición incierta ya que fue descrita sólo a partir de especímenes con frutos. Esta especie presenta características vegetativas muy parecidas a $S$. ahuatoso, pero se distingue por sus frutos piriformes (aunque la descripción original dice que son elipsoides), de hasta de $3.5 \mathrm{~cm}$ de largo y por tener 3 semillas por fruto, de ca. $2 \mathrm{~cm}$ de largo.

Localmente la madera de S. ahuatoso es muy apreciada por su resistencia; se utiliza en la construcción de casas.

\section{Agradecimientos}

A Martha Martínez Gordillo por la versión en latín de la descripción de la especie; a Ana Viniegra por la ilustración y a los habitantes de la localidad de El Molote por las facilidades otorgadas y su amable atención. Este trabajo es resultado de 2 proyectos: "Estudio de 3 localidades de bosque mesófilo en el estado de Guerrero", apoyado por el Consejo Nacional de Ciencia y Tecnología (clave 3164P-N9608) y "Diversidad florística de plantas epífitas en bosque mesófilo de Atoyac de Álvarez, Guerrero"( IN243704), apoyado por la Universidad Nacional Autónoma de México a través del Programa de Apoyo a Proyectos de Investigación e Innovación Tecnológica (PAPIIT).

\section{Literatura citada}

Lundell, C. L. 1975. Studies of American plants 1. X. Wrightia 5:148-149.

Smith, C. E. 1954. The new world species of Sloanea (Elaeocarpaceae). Contributions from the Gray Herbarium of Harvard University 175:1-114. 